\title{
The significance of Lactobacillus crispatus and $L$. vaginalis for vaginal health and the negative effect of recent sex: a cross-sectional descriptive study across groups of African women
}

Vicky Jespers ${ }^{1 *}$, Janneke van de Wijgert ${ }^{2}$, Piet Cools ${ }^{3}$, Rita Verhelst ${ }^{4}$, Hans Verstraelen ${ }^{5}$, Sinead Delany-Moretlwe ${ }^{6}$, Mary Mwaura ${ }^{7}$, Gilles F Ndayisaba ${ }^{8}$, Kishor Mandaliya ${ }^{7}$, Joris Menten ${ }^{9}$, Liselotte Hardy ${ }^{1,10}$, Tania Crucitti ${ }^{10}$ and for the Vaginal Biomarkers Study Group

\begin{abstract}
Background: Women in sub-Saharan Africa are vulnerable to acquiring HIV infection and reproductive tract infections. Bacterial vaginosis (BV), a disruption of the vaginal microbiota, has been shown to be strongly associated with HIV infection. Risk factors related to potentially protective or harmful microbiota species are not known.

Methods: We present cross-sectional quantitative polymerase chain reaction data of the Lactobacillus genus, five Lactobacillus species, and three BV-related bacteria (Gardnerella vaginalis, Atopobium vaginae, and Prevotella bivia) together with Escherichia coli and Candida albicans in 426 African women across different groups at risk for HIV. We selected a reference group of adult HIV-negative women at average risk for HIV acquisition and compared species variations in subgroups of adolescents, HIV-negative pregnant women, women engaging in traditional vaginal practices, sex workers and a group of HIV-positive women on combination antiretroviral therapy. We explored the associations between presence and quantity of the bacteria with BV by Nugent score, in relation to several factors of known or theoretical importance.
\end{abstract}

Results: The presence of species across Kenyan, South African and Rwandan women was remarkably similar and few differences were seen between the two groups of reference women in Kenya and South Africa. The Rwandan sex workers and HIV-positive women had the highest $G$. vaginalis presence $(p=0.006)$. Pregnant women had a higher Lactobacillus genus mean log (7.01 genome equivalents (geq)/ml) compared to the reference women ( $6.08 \mathrm{geq} / \mathrm{ml})$. $L$. vaginalis (43\%) was second to $L$. iners (81.9\%) highly present in women with a normal Nugent score. Recent sexual exposure negatively affected the presence of L. crispatus $(<0.001)$, L. vaginalis $(p=0.001)$, and Lactobacillus genus $(p<0.001)$. Having more than one sexual partner in the last three months was associated with an increased prevalence of $G$. vaginalis $(p=0.044)$ and $L$. iners $(p=0.001)$.

Conclusions: Although the composition of species across the studied African countries was similar, the presence of protective species i.e. L. crispatus and L. vaginalis in women with a normal Nugent score appeared lower compared to non-African studies. Furthermore, Lactobacillus species were negatively affected by sexual behavioural. Strategies to support protective Lactobacillus species are urgently needed.

(Continued on next page)

\footnotetext{
*Correspondence: vjespers@itg.be

'Department of Public Health, Unit of Epidemiology and Control of HIV/STD, Institute of Tropical Medicine, Nationalestraat 155, B-2000 Antwerp, Belgium Full list of author information is available at the end of the article
} 
(Continued from previous page)

Trial registration: The study is registered at the Trial Registration at the National Health Research Ethics Council South Africa with the number DOH2709103223.

Keywords: Bacterial vaginosis, Lactobacillus, reproductive health, Sexually transmitted infections, quantitative PCR, Sub-Saharan Africa, Vaginal microbiota, Sexual health, HIV prevention

\section{Background}

Bacterial vaginosis (BV) has been consistently associated with an increased risk of HIV infection and other sexually transmitted infections (STI) [1] as well as adverse clinical outcomes such as pelvic inflammatory disease [2], miscarriage [3], septic postpartum and neonatal infections [4]. BV can increase the risk of other STI which are in turn associated with HIV acquisition, including human papilloma virus and herpes simplex virus type 2 (HSV-2) infection [5-7]. While BV is a common condition worldwide, the highest prevalence is seen in sub-Saharan countries where HIV prevalence is highest [8]. BV is best described as a disruption of the vaginal microbiota or as a vaginal bacterial dysbiosis. It is characterised by a reduction or a replacement of the protective Lactobacillus species by an overgrowth of other anaerobic bacteria $[9,10]$.

Advances in molecular technologies, such as polymerase chain reaction (PCR) based techniques, have provided us with new insights and a more detailed characterisation of the vaginal microbiota; however, the aetiology of BV remains poorly understood. Data on the composition of the vaginal microbiota of African populations from regions with generalised HIV epidemics is still very limited. In order to design efficient biomedical interventions we need a better knowledge of the variations of the vaginal microbiota in healthy women at average risk of HIV infection and in women at high risk of HIV infection [11]. Further research is needed to address how the composition of the vaginal microbiota determines optimal vaginal and reproductive health. This knowledge may advance the development of novel interventions to prevent new HIV infections and address biological vulnerability in young adolescent women.

Our study examined individual vaginal bacterial species in women in sub-Saharan Africa and investigated correlations with vaginal health and associated factors. This paper will report cross-sectional quantitative PCR data of the Lactobacillus genus and the five most prevalent vaginal Lactobacillus species [12,13] as well as three BV-related bacteria (Gardnerella vaginalis, Atopobium vaginae, and Prevotella bivia), and Escherichia coli and Candida albicans in groups of women in sub-Saharan Africa. To address the research gap described above we studied the presence and concentrations of the species in women at different risk for HIV infection. We quantified the species in a reference group of adult HIVnegative women at average risk for HIV acquisition and compared species variations in subgroups of HIVnegative pregnant women, adolescents, women engaging in intravaginal practices, sex workers and a group of HIV-positive women on combination antiretroviral therapy. We explored the associations between presence and concentrations of the bacteria with country, group, and in relation to several factors of known or theoretical importance e.g. recent sexual exposure including a seminal plasma biomarker [14], current contraceptive use, and reproductive tract infections (RTI).

\section{Methods}

\section{Study design}

A total of 430 women were enrolled at three study sites in Mombasa, Kenya (KE), Kigali, Rwanda (RW) and Johannesburg, South Africa (SA) in 2010-2011 [15]. Participants were enrolled in the cohort in one of six pre-defined study groups: a reference group of 219 non-pregnant HIV-negative women (KE 110; SA 109), and pregnant women (KE 30; SA 30), adolescents (KE 30; SA 30), women practicing intravaginal practices (SA 30), self-declared sex workers (RW 30) or HIV-positive women (RW 30).

\section{Population}

The reference group consisted of women (18-35 years) who were at average risk for HIV acquisition, did not engage in traditional intravaginal practices and were not pregnant. The pregnant women were less than 14 weeks gestation. The non-pregnant adolescents were 16 or 17 years old. The non-pregnant women engaging in traditional intravaginal practices inserted substances (cloth/ lemon juice/detergents) other than water and/or fingers to clean, dry or tighten the vagina on a regular basis. The remaining HIV-negative women consisted of nonpregnant self-declared sex workers. The HIV-positive women were on antiretroviral treatment for at least 6 months, were currently asymptomatic and had a CD4 count of more than 350 cells/ $\mu$ l. Recruitment was as follows: healthy women for inclusion in the reference groups were recruited primarily through women's groups and subsequent snowballing in Mombasa County and through primary health care clinics in inner city Johannesburg. Women practicing intra-vaginal practices were identified 
as a sub-set of this group. Pregnant women were recruited at antenatal clinics in Mombasa County and inner city Johannesburg. Adolescents were recruited from youth groups in Mombasa County and from youth-friendly clinics in inner city Johannesburg. In Kigali, sex workers were recruited from the sex worker community and from a previous prospective HIV-incidence cohort at RU [16,17], using community mobilizers; and HIV-positive women were recruited from the Muhima hospital public HIV treatment clinic.

\section{Clinic visit and laboratory procedures}

The screening and eligibility assessment included testing for HIV infection, RTI (Chlamydia trachomatis (CT), Neisseria gonorrhoea (NG), Trichomonas vaginalis (TV), HSV-2 and syphilis, urinary tract infection and cervical dysplasia by Pap smear. Women were enrolled on day 9 (+/- 2 days) of the menstrual cycle with a maximum of two months after the screening visit. All visits were conducted by a qualified person and done in the language chosen by the participant. An interview was conducted on sexual behaviour and vaginal practices. Next, a physical and vaginal speculum examination was carried out by a clinician, including colposcopy. Vaginal swabs for quantitative polymerase chain reaction (qPCR) analysis were taken at the enrolment visit before any other samples to avoid contamination. More details on visits and procedures have been described previously [15]. Vaginal swabs (Copan Diagnostics, Inc., Murrieta, USA) were shipped in batches using a temperature-monitored dry shipper to the central laboratory at the Institute of Tropical Medicine (ITM) in Antwerp, Belgium. Vaginal Gram-stained smears were scored at the ITM using the Nugent method in which a Nugent score of 7-10 is classified as positive for BV, 4-6 is classified as intermediate and $0-3$ indicates a normal vaginal microbiota [18]. For the quantification of vaginal species, two vaginal swabs per woman were taken and stored at $-80^{\circ} \mathrm{C}$ until DNA extraction. The swabs were thawed for 30 minutes at room temperature and diluted phosphate buffered saline (PBS) $(1,200 \mu \mathrm{l} ; 1$ part PBS and 9 parts saline, $\mathrm{pH} 7.4)$ was added to each swab and vortexed for 15 seconds. One $\mathrm{ml}$ of each suspension was pooled to a final volume of $2 \mathrm{ml}$. An aliquot of $250 \mu \mathrm{l}$ was used for DNA extraction on the Abbott m24sp automated extraction platform (Abbott, Maidenhead, United Kingdom) according to the manufacturer's instructions. $200 \mu \mathrm{l}$ of eluted DNA was stored at $-80^{\circ} \mathrm{C}$ for the qPCR assays (Additional file 1). The eluted swab suspension was tested for the presence of prostate-specific antigen (PSA) using the Seratec PSA semiquant assay (Seratec Diagnostica, Göttingen, Germany). A volume of $150 \mu \mathrm{l}$ of the eluted swab suspension was centrifuged for $10 \mathrm{~min}$ at $13,000 \times \mathrm{g}$. After centrifugation, $120 \mu \mathrm{l}$ of supernatant was used for testing according to the manufacturer's instruction. The vaginal $\mathrm{pH}$ was measured using $\mathrm{pH}$ 3.6-6.1 paper strips pressed against the vaginal wall during the pelvic examination (Macherey-Nagel pH Fix 3.6-6.1, Düren, Germany). The RTI diagnostic tests used in this study have been described before [15].

\section{Quantitative PCR of selected organisms}

We designed or selected primers targeting the following genus and species which have previously been shown to be important members of the vaginal microbiota [19-22]: Lactobacillus genus, L. crispatus, L. iners, L. jensenii, L. gasseri, L. vaginalis, Gardnerella vaginalis, Atopobium vaginae, Prevotella bivia, E. coli [23], and C. albicans [10]. qPCR was performed at the ITM and at the University of Ghent, Ghent, Belgium, as follows: at the ITM, for Lactobacillus genus, L. crispatus, L. iners, L. jensenii, L. gasseri, and $L$. vaginalis, the $25 \mu \mathrm{l}$ PCR mixture contained $12.5 \mu \mathrm{l}$ Rotor-Gene SYBR Green RT-PCR Master mix (Rotor-Gene SYBR Green PCR Kit, Qiagen, Venlo, The Netherlands), $5 \mu \mathrm{l}$ DNA extract, $0.5-1.0 \mu \mathrm{M}$ of their respective primers (Integrated DNA Technologies, Leuven, Belgium), and RNase-Free Water provided with the Rotor-Gene SYBR Green PCR kit [13,21,22,24,25]. The amplification reactions were performed with the Rotor Gene Q MDx 5 plex (Qiagen, Venlo, The Netherlands). The qPCR reactions, at the University of Ghent, for $A$. vaginae, G. vaginalis, $P$. bivia and $E$. coli were performed in a reaction volume of $10 \mu \mathrm{l}$, containing $5 \mu \mathrm{l}$ of LightCycler 480R SYBR Green I Master (Roche Applied Science, Basel, Switzerland), 0.2-1.25 $\mu \mathrm{M}$ of their respective primers (Eurogentec, Liege, Belgium) and $2 \mu \mathrm{l}$ of DNA extract $[19,22,26,27]$. Amplification was carried out on the LightCycler $480^{\circ}$ and the LightCyclerR 480 Software Version 1.5 (Roche, Basel, Switzerland). Standard curves were constructed for each of the organisms with 6 standards by a tenfold dilution of the DNA stock in HPLC grade water. DNA of the lactobacilli was extracted from cultures of $L$. crispatus LMG $9479^{\mathrm{T}}$, L. gasseri LMG $9203^{\mathrm{T}}$, L. iners LMG $18914^{\mathrm{T}}$, L. jensenii LMG $6414^{\mathrm{T}}$ and $L$. vaginalis $\mathrm{LMG}$ $12891^{\mathrm{T}}$ grown at $35^{\circ} \mathrm{C} \pm 2^{\circ} \mathrm{C}$ on Columbia agar base (BBL, Becton Dickinson, Erembodegem, Belgium) and $5 \%$ horse blood under anaerobic conditions (Anaerocult A, Merck, VWR International, Leuven). The DNA was extracted from cultures of $A$. vaginae CCUG $38953^{\mathrm{T}}$, G. vaginalis ATCC14018 ${ }^{\mathrm{T}}$, E. coli $\mathrm{ACM} 1803^{\mathrm{T}}$ grown on TSA and 5\% sheep blood (Becton Dickinson, Erembodegem, Belgium) and P. bivia ATCC29303 ${ }^{\mathrm{T}}$ grown on Columbia agar (Becton Dickinson, Erembodegem, Belgium) at $37^{\circ} \mathrm{C} \pm 2^{\circ} \mathrm{C}$ under anaerobic conditions (BugBox, LedTechno, Heusden-Zolder, Belgium). After extraction, the DNA concentrations were determined using NanoDrop (Thermo Fisher scientific, Erembodegem, Belgium). The genomic concentrations were calculated 
using the described genomic sizes of the type strains. Both the standard curves and samples were run in duplicate. The number of bacteria was expressed as genome equivalents per $\mathrm{ml}$ (geq/ml).

\section{Data analysis}

Data analysis was performed using SAS 9.4 and R 3.0.1. Each participant contributed a single data point for each analysis. Data from the enrolment visit was used except for RTI diagnoses and information about sex partners, which was collected at screening. The study population characteristics and reproductive health and vaginal microbiota data (including vaginal $\mathrm{pH}$, Nugent scores, and $\mathrm{qPCR}$ bacterial presence and concentrations in log geq $/ \mathrm{ml}$ ) are described as medians with ranges for continuous variables and concentrations and percentages for categorical variables. qPCR data was expressed categorically as presence/absence, or alternatively presence was divided into three separate categories: Not quantifiable (1600 to $16.000 \mathrm{geq} / \mathrm{ml}$ ), $<10^{6} \mathrm{geq} / \mathrm{ml}, \geq 10^{6} \mathrm{geq} / \mathrm{ml}$. For quantifiable levels, mean and SD were calculated. A positive PSA result included both strong and weak reactions. We explored bivariate associations with chisquared tests of the presence/absence of each bacterial species (Lactobacillus genus excluded) with the following variables: country, group, age, parity, lifetime number of sexual partners, number of sexual partners in the last three months, reported recent vaginal sex, seminal factor PSA presence, colposcopic findings e.g. petechiae, erythema, presence of ectopy, HSV-2 serology, RTI (excluding HIV, HSV-2, Candida), products used to wash/ cleanse/dry/tighten, intravaginal cleansing during bathing, contraception, recent antibiotic use (excluding cotrimoxazole prophylaxis for the prevention of HIV-associated opportunistic infections), $\mathrm{BV}$, and vaginal $\mathrm{pH}$. For Lactobacillus genus we performed a simple linear regression analysis including the variables defined above. In the multivariate logistic regression, we report adjusted odds ratio (AOR) and 95\% confidence intervals $(\mathrm{CI})$; all variables meeting a $\mathrm{p}$-value of $\leq 0.05$ in the bivariate analysis were included, removing variables with a p-value of $<0.05$ in a stepwise manner. For Lactobacillus genus we performed a multiple linear regression analysis, reported as adjusted difference in means, including the variables meeting a p-value of $\leq 0.05$ from the simple regression analysis. We also constructed a multivariate logistic regression model that included selected species and clinically relevant variables to improve the interpretation of the data. The species and variables included in this model were: $L$. crispatus, L. iners, G. vaginalis, A. vaginae, Lactobacillus genus, parity, PSA, number of sexual partners within the last three months, reported intravaginal cleansing during bathing, recent antibiotic use, and contraception use. We included intravaginal cleansing during bathing as this was a highly prevalent behaviour in our study population. We further included contraceptive use in the model because the controversial discussion of the effect of progesterone depot on the acquisition of HIV. This analysis was performed on the reference group and on all women.

\section{Ethics statement}

Written information and consent forms in the local language were provided. After the interview, the participants and, in case they were of minor age/not emancipated (age below 18 in South Africa and Kenya and below 21 in Rwanda), the parents or guardians were asked to confirm their willingness to participate in the study by signing or marking the consent form. The protocol was approved by the Kenyatta National Hospital Ethical Review Committee, Kenya; the Human Research Ethics Committee, University of the Witwatersrand, SA; the Rwanda National Ethics Committee, Rwanda; the Institutional Review Boards of the Institute of Tropical Medicine in Antwerp, of Ghent University, and of the University Teaching Hospital in Antwerp, Belgium. In addition the study was approved by the National Council on Science and Technology in Kenya; the SA Department of Health; and the National AIDS Control Commission in Rwanda.

\section{Results}

qPCR data were not available for four women leaving 426 women for the analysis. Nugent score data were available for 387 of the 426 women due to unreadable Gram stain smears.

The mean age of the reference group was 25 years (Additional file 2). Women in the other study groups had a similar mean age (24-26 years), except for the adolescents who were 16-17 years old, and the HIVpositive women who had a mean age of 31 years. Contraceptive use in the reference group was $80.4 \%$; the most commonly used methods were condoms $(24 \%)$ and progestin-only injections (36\%). Among adolescents, overall contraceptive use was low (65\%); the most common method was condoms (50\%). Seventy-five per cent of women in the reference group had one or more children. Parity was highest in the vaginal practices group (84\%), the sex workers (97\%) and HIV-positive women (90\%). Intravaginal cleansing during bathing was frequently in all groups (including the reference group), with exception of pregnant women who reported less intravaginal cleansing (28\%). While the majority of women stated having one sex partner in the past three months (reference group 90\%), with exception of sex workers who reported many more partners. Systemic antibiotics were used by 62 women (14\%) within 14 days prior to the enrolment visit. The last day of antibiotic 
use was on average 7 days (median 7 days) prior to the enrolment visit.

\section{Prevalence of $\mathrm{BV}, \mathrm{pH}$ and PSA}

Overall, 57.5\% of women presented with a normal Nugent score, $7.1 \%$ with an intermediate score and $35.4 \%$ with a BV score. The BV prevalence was $33 \%$ in the reference group, $30 \%$ for pregnant women, $30 \%$ in adolescents, $37 \%$ in vaginal practice users, $48 \%$ for women living with HIV, and $68 \%$ for sex workers. The overall mean vaginal $\mathrm{pH}$ was $4.7(\mathrm{SD}=0.7)$ with the majority (68\%) of women having a $\mathrm{pH}$ between four and five (Additional file 3). Ten per cent of women had a pH below four. PSA was present for $39 \%$ of the reference group, $38 \%$ in the adolescents, $44 \%$ among women living with $\mathrm{HIV}, 45 \%$ in the vaginal practices users, $56 \%$ in pregnant women, and $57 \%$ in sex workers. Further results by group are presented in Table 1 .

\section{A comparison of the presence and concentrations of species and Lactobacillus genus across countries and groups}

The presence of species and Lactobacillus genus across Kenyan, South African and Rwandan women was remarkably similar and there was no evidence of differences between the two large groups of reference women in Kenya and South Africa (Figure 1, Tables 1 and 2, Additional file 3). There was strong evidence for differences among the Rwandan sex worker group. The Rwandan sex workers had the highest G. vaginalis presence $(\mathrm{p}=0.006)$ and the lowest $L$. jensenii presence (6.7\% RW, 19\% KE, 21.7\% SA; p =0.031). Also, E. coli was present in $70 \%$ of Rwandan sex workers compared to $20 \%$ in Rwandan HIV-positive women, $25 \%$ in women in Kenya and 26\% in SA ( $\mathrm{p}=0.009)$. High concentrations of Lactobacillus genus $\left(>10^{6} \mathrm{geq} / \mathrm{ml}\right)$ were present in $69 \%$ of all women and low concentrations $\left(10^{3}\right.$ to $10^{6}$ $\mathrm{geq} / \mathrm{ml}$ ) in $15 \%$ (a distribution of the species log concentrations is shown in Additional file 4). L. iners, L. crispatus, $L$. jensenii, $L$. vaginalis, and $L$. gasseri were detected in high concentrations ( $>10^{6}$ geq $/ \mathrm{ml}$ ) in $58 \%, 20 \%, 13 \%, 10 \%$ and $3 \%$ of women, respectively. In the reference group 91.7\% of women had lactobacilli detected as measured by Lactobacillus genus-level PCR. This proportion was lowest for HIV-positive women (80\%) and for adolescents (86.4\%). The Lactobacillus genus mean log was 6.39 geq/ $\mathrm{ml}$ for Kenyan women which was higher than the mean $\log$ for Rwandan $(5.93 \mathrm{geq} / \mathrm{ml})$ and South African (5.95 $\mathrm{geq} / \mathrm{ml})$ women $(\mathrm{p}=0.235)$. Pregnant women, in particular in Kenya, had a higher mean log of Lactobacillus genus $(7.01 \mathrm{geq} / \mathrm{ml})$ compared to the reference women $(6.08$ $\mathrm{geq} / \mathrm{ml} ; \mathrm{p}=0.013)$. Interestingly, South African adolescents had the lowest mean log Lactobacillus genus (4.26 geq $/ \mathrm{ml}, \mathrm{p}<0.001$ ) whereas Kenyan adolescent had a high mean $\log$ of $6.97 \mathrm{geq} / \mathrm{ml}$ when comparing groups and country. Further, adolescents had low P. bivia presence compared to the reference group $(\mathrm{p}<0.001)$. C. albicans was detected in $12 \%$ of reference women and similar proportions were found in the other groups $(\mathrm{p}=0.524)$.

\section{Reproductive health, sexual behaviour and the presence and concentrations of qPCR microbiota}

Parity was negatively associated with $L$. vaginalis and $L$. iners in a bimodal way. Having one or two children was associated with a lower prevalence of $L$. vaginalis (22.4\%) compared to women with no children (34.2\%) and women with more than two children (33.3\%) (AOR $0.56 ; 95 \%$ CI $0.35,0.91 ; \mathrm{p}=0.05$ ). This association was similar for the reference group ( $20 \%$ vs $37.9 \%$ vs $38.5 \%$; AOR 0.41; 95\% CI 0.20, 0.82). Further, having more than two children was associated with lower detection of $L$. iners (AOR 0.35; 95\% CI 0.18,0.66; p=0.002). Finally, having any number of children was strongly associated with the presence of C. Albicans (AOR 3.7; 95\% CI 1.59, 8.61 for 1-2 children and AOR 2.54; 95\% CI 0.85,7.56 for more than 2 children; $\mathrm{p}=0.006$ ). We found several sexual behavioural factors associated with presence and concentrations of species. L. crispatus (AOR 0.33; 95\% CI $0.20,0.56 ; \mathrm{p}<0.001$ ) and $L$. vaginalis presence (AOR $0.47 ; 95 \%$ CI $0.3,0.75 ; \mathrm{p}=0.001$ ) was negatively associated with recent sexual exposure as measured by PSA detection, as were the Lactobacillus genus concentrations (adjusted difference in means -1.01; 95\% CI:-1.51,-0.51; $\mathrm{p}<$ $0.001)$. This strongly negative association of $L$. crispatus and PSA remained in the sub-analysis of the reference group (AOR 0.35; 95\% CI 0.17,0.72; $\mathrm{p}=0.002$ ). Additionally, having more than one sexual partner in the last three months was positively associated with the presence of E. coli $(51.1 \%$ vs $23.1 \%$; OR 3.48, $95 \%$ CI $1.18,10.30$; p $=0.003)$, L. iners (66.7\% vs $42.3 \%$; AOR 3.1, 95\% CI 1.12, $8.57 ; \mathrm{p}=0.001)$ and $G$. vaginalis $(66.7 \%$ vs $34.6 \%$; AOR 3.57, 95\% CI 1.28,9.97; $\mathrm{p}=0.045$ ). There was no evidence of an association between the number of lifetime partners and the presence of species except for a modest positive association with the presence of $P$. bivia and $E$. coli. The reporting of recent vaginal sex, similarly, was only associated with $P$. bivia.

The detection of HSV-2 antibodies was negatively associated with $L$. crispatus in all women; additionally HSV-2 was negatively correlated with Lactobacillus genus (mean $\log -0.74 ; 95 \% \mathrm{CI}:-1.46,-0.02 ; \mathrm{p}=0.045$ ) in the reference group. The detection of an RTI at screening (CT, NG, TV, or syphilis), was negatively associated with $L$. crispatus, $L$. jensenii $(9.6 \%$ vs $20.4 \%)$ and $L$. vaginalis, and positively associated with $G$. vaginalis and $A$. vaginae presence. None of the variables: abnormal colposcopic findings, products used to wash/cleanse/dry/ tighten, or cleansing during bathing, showed an 
Table 1 Presence and concentrations of vaginal microbiota species

\begin{tabular}{|c|c|c|c|c|c|c|c|c|c|}
\hline & \multicolumn{2}{|c|}{ Reference group } & \multicolumn{2}{|c|}{ Pregnant women } & \multicolumn{2}{|c|}{ Adolescents } & \multirow{2}{*}{$\begin{array}{l}\text { Intravaginal } \\
\text { practices } \\
\text { South Africa } \\
N=30\end{array}$} & \multirow{2}{*}{$\begin{array}{l}\text { Sex } \\
\text { workers } \\
\text { Rwanda } \\
N=30\end{array}$} & \multirow{2}{*}{$\begin{array}{l}\text { HIV- } \\
\text { positive } \\
\text { Rwanda } \\
\mathrm{N}=30\end{array}$} \\
\hline & $\begin{array}{l}\text { Kenya } \\
N=109\end{array}$ & $\begin{array}{l}\text { South Africa } \\
N=108\end{array}$ & $\begin{array}{l}\text { Kenya } \\
\mathrm{N}=30\end{array}$ & $\begin{array}{l}\text { South Africa } \\
N=30\end{array}$ & $\begin{array}{l}\text { Kenya } \\
\mathrm{N}=\mathbf{2 9}\end{array}$ & $\begin{array}{l}\text { South Africa } \\
N=30\end{array}$ & & & \\
\hline $\begin{array}{l}\text { Presence of species } \\
\text { by } q P C R\end{array}$ & N (\%) & N (\%) & N (\%) & N (\%) & N (\%) & N (\%) & N (\%) & N (\%) & N (\%) \\
\hline Lactobacillus genus & 101(93) & $98(91)$ & $30(100)$ & $30(100)$ & 27(93) & $24(80)$ & 28(93) & 28(93) & $24(80)$ \\
\hline Lactobacillus crispatus & $29(27)$ & $26(24)$ & $6(20)$ & $7(23)$ & $11(38)$ & $6(20)$ & $5(17)$ & $5(17)$ & $5(17)$ \\
\hline Lactobacillus iners & $75(69)$ & $82(76)$ & $24(80)$ & $23(77)$ & $23(79)$ & $20(67)$ & $26(87)$ & $18(60)$ & $19(63)$ \\
\hline Lactobacillus jensenii & $19(17)$ & $25(23)$ & $6(20)$ & $10(23)$ & $7(24)$ & $2(7)$ & $6(20)$ & $1(3)$ & $3(10)$ \\
\hline Lactobacillus gasseri & $7(6)$ & $8(7)$ & $3(10)$ & $3(10)$ & $4(14)$ & $2(7)$ & $2(7)$ & $4(13)$ & $3(10)$ \\
\hline Lactobacillus vaginalis & $33(30)$ & $28(26)$ & $9(30)$ & $7(23)$ & $14(48)$ & $7(23)$ & $5(17)$ & $8(27)$ & $9(30)$ \\
\hline Gardnerella vaginalis & $59(54)$ & $49(45)$ & $14(47)$ & $15(50)$ & $17(59)$ & $19(63)$ & $16(53)$ & $23(73)$ & $21(70)$ \\
\hline Atopobium vaginae & $46(42)$ & $37(34)$ & $9(30)$ & $11(37)$ & $10(34)$ & $19(43)$ & $11(37)$ & $17(57)$ & $14(47)$ \\
\hline Prevotella bivia & $97(89)$ & $83(77)$ & 29(97) & $21(70)$ & $24(83)$ & $12(40)$ & $22(63)$ & $30(100)$ & $27(70)$ \\
\hline Escherichia coli & $28(26)$ & $29(27)$ & $6(20)$ & $10(23)$ & $8(28)$ & $4(13)$ & $9(30)$ & $21(70)$ & $6(20)$ \\
\hline Candida albicans & $15(14)$ & $12(11)$ & $4(13)$ & 1(3) & $3(10)$ & 0 & $5(17)$ & $4(13)$ & $3(10)$ \\
\hline $\begin{array}{l}\text { Vaginal species } \\
\text { concentrations by } q P C R^{1}\end{array}$ & Mean (SD) & Mean (SD) & Mean (SD) & Mean (SD) & Mean (SD) & Mean (SD) & Mean (SD) & Mean (SD) & Mean (SD) \\
\hline Lactobacillus genus & $6.4(2.1)$ & $6.9(1.7)$ & $7.5(1)$ & $6.5(2.3)$ & $7.5(1.1)$ & $5.3(2.5)$ & $6.4(2.1)$ & 7.1(1.7) & $6.5(2.4)$ \\
\hline Lactobacillus crispatus & $6.8(2.2)$ & $7.2(1.6)$ & $8(0.4)$ & $7.6(1.5)$ & $7.3(2.2)$ & 7.1(1.3) & $7.5(1.3)$ & $7.8(1.1)$ & $4.7(3.4)$ \\
\hline Lactobacillus iners & $6.6(2.2)$ & $7(2)$ & $7.6(1.1)$ & $6.9(1.6)$ & $7.4(1.7)$ & $4.9(3.1)$ & $6.7(2.3)$ & $8.1(1.1)$ & $7.3(2.4)$ \\
\hline Lactobacillus jensenii & $5.6(2.5)$ & $6.3(1.9)$ & $6.6(1)$ & $7.7(0.9)$ & $5.5(3.1)$ & 3.5(3.6) & $5(3.2)$ & $8.3(\mathrm{NA})$ & $6.3(1)$ \\
\hline Lactobacillus gasseri & $3.3(2.9)$ & $5.3(1.9)$ & $6.3(1.3)$ & $5.1(3.8)$ & $4.7(2.5)$ & $6.4(0.4)$ & $3.8(4)$ & $4.1(3.5)$ & $1(N A)$ \\
\hline Lactobacillus vaginalis & $2.6(3)$ & $3.8(3.2)$ & $3.9(3.4)$ & $4.4(3.9)$ & $5.2(2.8)$ & $6.2(0.7)$ & $3.1(4.4)$ & $4.8(3.2)$ & $4.1(2.7)$ \\
\hline Gardnerella vaginalis & $5.4(1.1)$ & $5.3(0.9)$ & $5.5(1.2)$ & $5.2(0.9)$ & $5.5(0.8)$ & $4.6(1.2)$ & $5.2(1.4)$ & $6.2(1)$ & $5.6(1)$ \\
\hline Atopobium vaginae & $5.5(1.8)$ & $5.1(1.5)$ & $7(1)$ & $5.2(1.7)$ & $5.4(2.4)$ & $5(1.7)$ & $5.7(1.3)$ & $6.6(1.8)$ & $5.5(1.5)$ \\
\hline Prevotella bivia & $3.1(1.2)$ & $3.2(1.1)$ & $3.1(1.3)$ & $3.3(0.9)$ & $3.3(1.3)$ & $3.2(1.1)$ & $3.5(1.1)$ & $3.6(1.1)$ & $3.3(1)$ \\
\hline Escherichia coli & $5.2(0.4)$ & $5.1(0.6)$ & $5(0.5)$ & $5.2(0.5)$ & $5.1(0.4)$ & $4.8(0.3)$ & $4.9(0.3)$ & $5.3(0.6)$ & $5.9(1.1)$ \\
\hline Candida albicans & $4.9(1.3)$ & $5.1(0.7)$ & $5.7(1)$ & 4.6(NA) & $6(0.7)$ & $O(N A)$ & $5.3(0.8)$ & $5.4(1.2)$ & $4.9(0.2)$ \\
\hline \multicolumn{10}{|l|}{$\begin{array}{l}\text { Nugent score } e^{2} \text { and } \\
\text { vaginal } \mathrm{pH}\end{array}$} \\
\hline Vaginal pH & $5.1(0.9)$ & $4.5(0.6)$ & $4.8(0.8)$ & $4.3(0.5)$ & $4.7(0.7)$ & $4.4(0.6)$ & $4.6(0.6)$ & $5.1(0.6)$ & $4.7(0.6)$ \\
\hline Nugent 0-3: normal & $55(56)$ & $63(66)$ & $19(68)$ & $18(62)$ & $18(67)$ & $13(45)$ & $16(59)$ & $6(24)$ & $13(48)$ \\
\hline Nugent 4-6: intermediate & $8(8)$ & $6(6)$ & $1(4)$ & $2(7)$ & $4(15)$ & $4(14)$ & $1(4)$ & 2(8) & $1(4)$ \\
\hline $\begin{array}{l}\text { Nugent 7-10: bacterial } \\
\text { vaginosis }\end{array}$ & $36(36)$ & $27(28)$ & $8(29)$ & $9(31)$ & 5(19) & $12(41)$ & $10(37)$ & $17(68)$ & $13(48)$ \\
\hline
\end{tabular}

Quantitative PCR data was available for 426 of the 430 women. ${ }^{1}$ mean (SD) quantity log concentrations of the microbiota for women who had that particular species detected and quantified as log genome equivalents $/ \mathrm{ml} .{ }^{2}$ Nugent score data were available for 387 of the 426 women due to unreadable Gram stained slides. qPCR: quantitative polymerase chain reaction.

association with the species. The presence of ectopy was associated with increased $E$. coli presence (35.9\% vs $22 \%$; AOR 1.78, 95\% CI 1.12,2.83; p = 0.002). Additionally, reported antibiotics use in the past 14 days was associated with a higher presence of G. vaginalis (AOR 2.23; 95\% CI $1.33,3.74 ; \mathrm{p}=0.035$ ) and $A$. vaginae (AOR 1.79; $95 \%$ CI 1.11,2.90; $\mathrm{p}=0.017)$. And finally, C. albicans was more often present in women using progesterone-only
(OR 1.96; 95\% CI 1.0,3.86) or combined hormones (OR 2.47; 95\% CI 1.06,5.81; $\mathrm{p}=0.050)$.

\section{Association with Nugent score and $\mathrm{pH}$}

As expected, there was a strong positive association between $L$. crispatus (34.8\% vs $5.8 \%)$, L. jensenii (28.5\% vs $4.4 \%)$, L. vaginalis $(43 \%$ vs $6.6 \%)$, L. iners $(81.9 \%$ vs $67.2 \%)$ and $L$. gasseri (10.4\% vs 3.6\%) and a Nugent score 


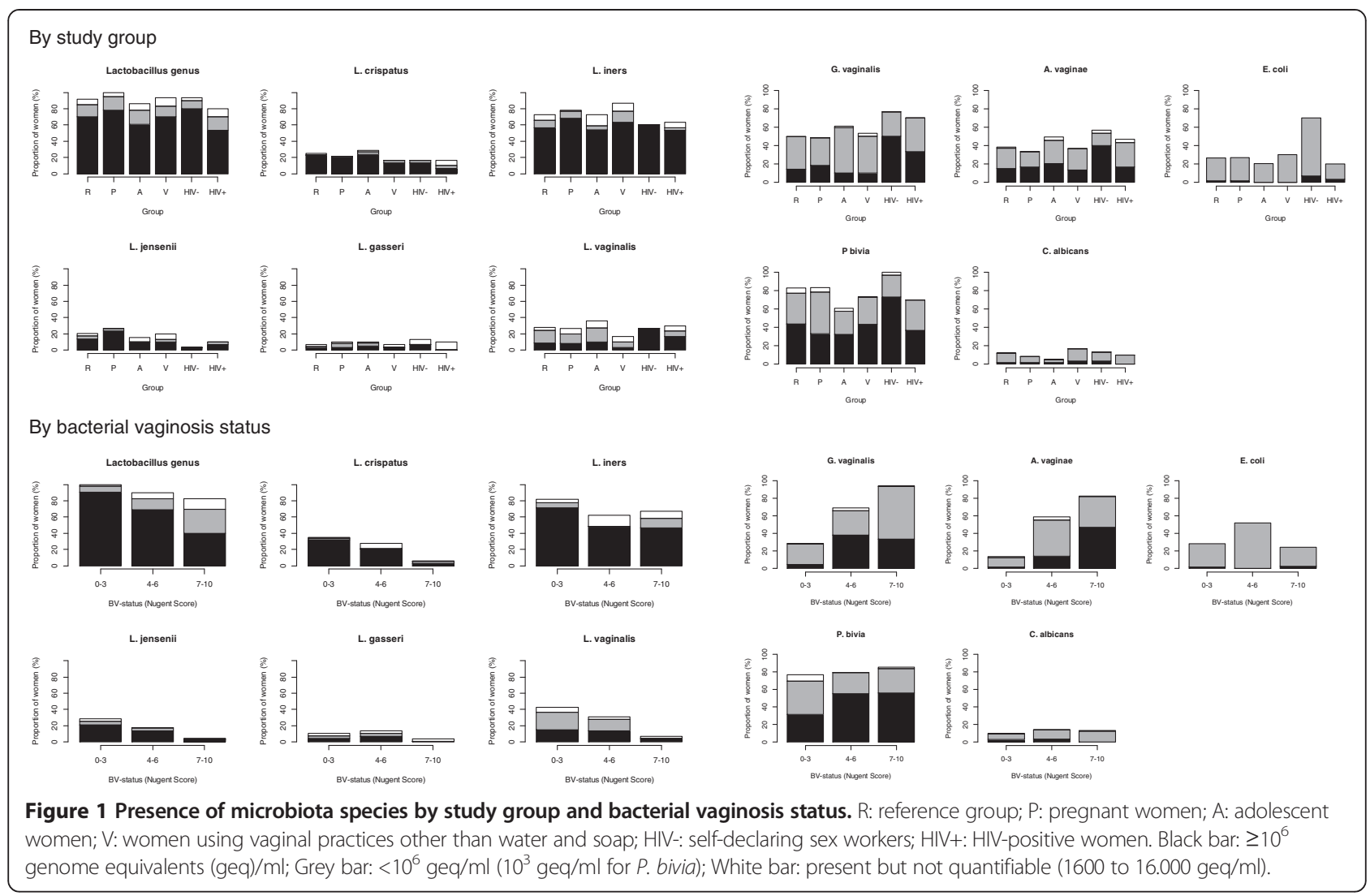

0-3 compared to a Nugent score 7-10 in both the reference group $(\mathrm{p}<0.001$ to $\mathrm{p}=0.023)$ and in all women $(\mathrm{p}<0.001$ to $\mathrm{p}=0.042)$ (Figure 1$)$. Similarly, there was a strong positive association between $A$. vaginae (94.2\% vs $28.1 \%$ ) and G. vaginalis $(82.5 \%$ vs $13.6 \%$ ) and a Nugent score of 7-10 compared to Nugent score $0-3$ in both all women and in the reference group $(\mathrm{p}<0.001)$. E. coli presence was higher $(51.7 \%)$ in women with an intermediate BV score $(\mathrm{p}=0.011)$ compared to women with no BV (28.1\%) and women with BV (24.1\%). There was no evidence of an association between $P$. bivia and $C$. albicans and Nugent score. Vaginal $\mathrm{pH}$ was negatively correlated with Lactobacillus species, with the exception of $L$. iners. For example, L. crispatus was present in $67.4 \%$ of women with a pH below 4 and in $9.8 \%$ of women with a $\mathrm{pH}$ above 5.5 and for $L$. vaginalis proportions were $58.1 \%$ vs $11.8 \%$. In contrast, the proportions for $L$. iners were $74.4 \%$ vs $70.6 \%$.

\section{A model summarising the associations between species and relevant clinical variables}

There was a negative association between $L$. iners and increased parity in both the reference women and all women (Table 3 presents OR and 95\% CIs). For both the reference group and all women, the negative association between the seminal factor PSA and L. crispatus was confirmed, as well as a reduced Lactobacillus genus concentration by about one log. Similarly, for the reference group and all women, having more than one sexual partner in the last three months was positively associated with $L$. iners and G. vaginalis presence. Recent antibiotic use was associated with a higher prevalence of G. vaginalis and $A$. vaginae in all women, but this association was not seen in the analysis of the reference women. There was no evidence of an association with intravaginal cleansing during bathing in the analysis for all women, but there was a strong association with the microbiota in the reference women: a negative association with $A$. vaginae and positive association with Lactobacillus genus. In the reference group, women using progesterone-only and combined hormones had a lower presence of A. vaginae and G. vaginalis as compared to women not using contraceptives or using none hormonal contraceptive methods.

\section{Discussion}

This study characterised key microbiota in the female genital tract, and compared their presence and concentrations among healthy women at average risk to those at high risk of HIV infection in three sites in subSaharan Africa. The presence of species and Lactobacillus genus across Kenyan, South African and Rwandan 
Table 2 Univariate and multivariate analysis of factors associated with vaginal Lactobacillus, and BV-related species presence ${ }^{1}$

\begin{tabular}{|c|c|c|c|c|c|c|c|c|c|c|c|c|}
\hline$N=426$ & & L. crispatus & & L. iners & & L. vaginalis & & G. vaginalis & & A. vaginae & & P. bivia \\
\hline & $\%$ & $\mathrm{OR}(\mathrm{Cl})$ & $\%$ & $\mathrm{OR}(\mathrm{Cl})$ & $\%$ & $\mathrm{OR}(\mathrm{Cl})$ & $\%$ & $\mathrm{OR}(\mathrm{Cl})$ & $\%$ & $\mathrm{OR}(\mathrm{Cl})$ & $\%$ & $\mathrm{OR}(\mathrm{Cl})$ \\
\hline Country & & $p=0.207$ & & $p=0.084$ & & $p=0.126$ & & $p=0.006$ & & $p=0.182$ & & $\mathrm{p}=<0.001$ \\
\hline Kenya & 27.4 & & 72.6 & & 33.3 & & 53.6 & Ref & 38.7 & & 89.3 & Ref \\
\hline Rwanda & 16.7 & & 61.7 & & 28.3 & & 73.3 & $2.38(1.25,4.55)$ & 51.7 & & 85.0 & $0.68(0.29,1.61)$ \\
\hline South Africa & 22.2 & & 76.3 & & 23.7 & & 50.0 & $0.87(0.57,1.31)$ & 39.4 & & 69.7 & $0.28(0.16,0.49)$ \\
\hline Group & & $p=0.580$ & & $p=0.174$ & & $p=0.591$ & & $p=0.026$ & & $p=0.190$ & & $p=<0.001$ \\
\hline Reference group & 25.3 & & 72.4 & & 28.1 & & 49.8 & Ref & 38.2 & & 82.9 & Ref \\
\hline Pregnant women & 21.7 & & 78.3 & & 26.7 & & 48.3 & $0.94(0.53,1.67)$ & 33.3 & & 83.3 & $1.03(0.48,2.21)$ \\
\hline Adolescents & 28.8 & & 72.9 & & 35.6 & & 61.0 & $1.58(0.88,2.84)$ & 49.2 & & 61.0 & $0.32(0.17,0.61)$ \\
\hline Intravaginal practices & 16.7 & & 86.7 & & 16.7 & & 53.3 & $1.15(0.54,2.48)$ & 36.7 & & 73.3 & $0.57(0.23,1.37)$ \\
\hline Sex workers & 16.7 & & 60.0 & & 26.7 & & 76.7 & $3.32(1.37,8.05)$ & 56.7 & & 100 & No estimate \\
\hline HIV-positive women & 16.7 & & 63.3 & & 30.0 & & 70.0 & $2.35(1.03,5.37)$ & 46.7 & & 70.0 & $0.48(0.2,1.37)$ \\
\hline Age & & $p=0.376$ & & $p=0.046$ & & $p=0.554$ & & $p=0.640$ & & $p=0.556$ & & $p=<0.001$ \\
\hline$<18$ years & 28.8 & & 72.9 & Ref & 35.6 & & 61.0 & & 49.2 & & 61.0 & Ref \\
\hline $18-24$ years & 20.3 & & 77.0 & $1.25(0.63,2.49)$ & 25.7 & & 56.1 & & 40.5 & & 84.5 & $3.98(1.93,8.24)$ \\
\hline $25-29$ years & 21.7 & & 75.4 & $1.14(0.57,2.27)$ & 27.5 & & 52.2 & & 39.1 & & 83.3 & $3.37(1.62,7.03)$ \\
\hline 30 years or more & 28.4 & & 60.5 & $0.57(0.28,1.18)$ & 28.4 & & 51.9 & & 38.3 & & 77.8 & $2.46(1.08,5.58)$ \\
\hline Parity & & $p=0.106$ & & $p=\mathbf{0 . 0 0 1}$ & & $p=0.03$ & & $p=0.418$ & & $p=0.840$ & & $p=0.164$ \\
\hline 0 & 27.5 & & 76.5 & Ref & 34.2 & Ref & 54.4 & & 40.3 & & 75.2 & \\
\hline $1-2$ & 19.2 & & 75.7 & $0.96(0.59,1.56)$ & 22.4 & $0.56(0.35,0.89)$ & 57.0 & & 42.1 & & 83.2 & \\
\hline$>2$ & 28.6 & & 54.0 & $0.36(0.19,0.67)$ & 33.3 & $0.96(0.51,1.79)$ & 47.6 & & 38.1 & & 77.8 & \\
\hline $\mathrm{RTI}^{2}$ & & $p=\mathbf{0 . 0 1 4}$ & & $p=0.406$ & & $p=0.031$ & & $p=0.019$ & & $p=\mathbf{0 . 0 0 3}$ & & $p=0.977$ \\
\hline No RTI & 25.8 & Ref & 72.0 & & 30.3 & Ref & 52.1 & Ref & 37.7 & Ref & 79.6 & \\
\hline 1 or more RTI & 12.3 & $0.40(0.19,0.85)$ & 76.7 & & 17.8 & $0.50(0.26,0.95)$ & 67.1 & $1.88(1.10,3.19$ & 56.2 & $2.12(1.27,3.53)$ & 79.5 & \\
\hline $\mathrm{Nr}$ of sexual partners last 3 months ${ }^{3}$ & & $p=0.060$ & & $p=<0.001$ & & $p=0.669$ & & $p=\mathbf{0 . 0 3 3}$ & & $p=0.129$ & & $p=0.053$ \\
\hline 0 & 42.3 & & 42.3 & Ref & 30.8 & & 34.6 & Ref & 30.8 & & 76.9 & Ref \\
\hline 1 & 22.5 & & 75.8 & $4.27(1.89,9.64)$ & 27.3 & & 54.6 & $2.28(0.99,5.24)$ & 40 & & 78.0 & $1.07(0.41,2.74)$ \\
\hline$>1$ & 20.0 & & 66.7 & $2.73(1.01,7.37)$ & 33.3 & & 66.7 & $3.78(1.36,10.46)$ & 53.3 & & 93.3 & $4.2(0.95,18.54)$ \\
\hline Seminal factor PSA present ${ }^{4}$ & & $p=<0.001$ & & $p=0.464$ & & $p=<0.001$ & & $p=0.259$ & & $p=0.308$ & & $p=0.128$ \\
\hline No & 32.1 & Ref & 70.9 & & 34.6 & Ref & 52.1 & & 38.5 & & 82.9 & \\
\hline Yes & 13.2 & $0.32(0.19,0.54)$ & 74.2 & & 19.8 & $0.47(0.3,0.73)$ & 57.7 & & 43.4 & & 76.9 & \\
\hline
\end{tabular}

Results that remained significant (using a $p=0.05$ cut-off) in the multivariate logistic regression are depicted in bold. ${ }^{1}:$ Univariate analysis with $p$-values from chi-squared tests; ${ }^{2}$ RTI: excluding HIV, HSV-2, Candida. ${ }^{3}$ Data collected at the screening visit up to two months before the enrolment visit. ${ }^{4}$ Prostate specific antigen present in vaginal fluid, including weak reaction. RTI: reproductive tract infections. 
Table 3 Factors associated with L. crispatus, L. iners, G. vaginalis, A. vaginae and Lactobacillus genus: results from a multiple logistic regression model for the reference women and for all women

\begin{tabular}{|c|c|c|c|c|c|}
\hline Reference women $\mathrm{N}=217$ & L. crispatus & L. iners & G. vaginalis & A. vaginae & Lactobacillus genus* \\
\hline & $\mathrm{OR}(\mathrm{Cl})$ & $\mathrm{OR}(\mathrm{Cl})$ & $\mathrm{OR}(\mathrm{Cl})$ & $\mathrm{OR}(\mathrm{Cl})$ & Log concentrations (Cl) \\
\hline Parity & $p=0.831$ & $p=\mathbf{0 . 0 0 3}$ & $p=0.587$ & $p=0.265$ & $p=0.179$ \\
\hline 0 & Ref & Ref & Ref & Ref & Ref \\
\hline $1-2$ & $0.82(0.36,1.88)$ & $0.43(0.18,1.05)$ & $1.40(0.67,2.93)$ & $1.81(0.85,3.86)$ & $-0.79(-1.67,0.10)$ \\
\hline$>2$ & $1.01(0.36,2.86)$ & $0.16(0.05,0.47)$ & $1.07(0.41,2.75)$ & $1.93(0.72,5.16)$ & $-0.91(-2.06,0.24)$ \\
\hline Seminal factor present & $p=\mathbf{0 . 0 0 3}$ & $p=0.715$ & $p=0.773$ & $p=0.435$ & $p=\mathbf{0 . 0 1 6}$ \\
\hline No & Ref & Ref & Ref & Ref & Ref \\
\hline Yes & $0.34(0.16,0.72)$ & $1.13(0.58,2.23)$ & $1.09(0.60,1.97)$ & $1.27(0.69,2.34)$ & $-0.89(-1.61,-0.17)$ \\
\hline Nr of sexual partners last 3 months ${ }^{1}$ & $p=0.901$ & $p=0.049$ & $p=\mathbf{0 . 0 4 9}$ & $p=0.204$ & $p=0.667$ \\
\hline 0 & Ref & Ref & Ref & Ref & Ref \\
\hline 1 & $1.16(0.36,3.72)$ & $3.90(1.27,11.94)$ & $4.17(1.22,14.23)$ & $2.14(0.63,7.32)$ & $0.49(-0.84,1.83)$ \\
\hline$>1$ & $0.74(0.06,9.56)$ & $1.97(0.22,17.63)$ & $3.12(0.34,28.91)$ & $6.83(0.74,63.15)$ & $-0.15(-2.74,2.44)$ \\
\hline Intravaginal cleansing during bathing & $p=0.420$ & $p=0.208$ & $p=0.281$ & $p=\mathbf{0 . 0 2 3}$ & $p=\mathbf{0 . 0 0 7}$ \\
\hline No & Ref & Ref & Ref & Ref & Ref \\
\hline Yes & $1.33(0.66,2.65)$ & $1.55(0.78,3.09)$ & $0.72(0.39,1.31)$ & $0.49(0.26,0.91)$ & $1.01(0.28,1.75)$ \\
\hline Contraception use & $p=0.259$ & $p=0.368$ & $p=\mathbf{0 . 0 0 8}$ & $p=\mathbf{0 . 0 1 5}$ & $p=0.606$ \\
\hline None/Non-Hormonal & Ref & Ref & Ref & Ref & Ref \\
\hline Hormonal & $0.66(0.32,1.36)$ & $1.39(0.68,2.82)$ & $0.42(0.22,0.88)$ & $0.44(0.22,0.86)$ & $0.21(-0.58,0.99)$ \\
\hline Recent antibiotic use & $p=0.360$ & $p=0.704$ & $p=0.697$ & $p=0.383$ & $p=0.980$ \\
\hline No & Ref & Ref & Ref & Ref & Ref \\
\hline Yes & $0.63(0.23,1.73)$ & $0.83(0.33,2.13)$ & $1.18(0.51,2.72)$ & $1.45(0.63,3.35)$ & $-0.01(-1.03,1.00)$ \\
\hline All women $\mathrm{N}=426$ & L. crispatus & L. iners & G. vaginalis & A. vaginae & Lactobacillus genus* \\
\hline Parity & $p=0.324$ & $p=\mathbf{0 . 0 0 2}$ & $p=0.477$ & $p=0.793$ & $p=0.763$ \\
\hline 0 & Ref & Ref & Ref & Ref & Ref \\
\hline $1-2$ & $0.76(0.43,1.36)$ & $0.94(0.54,1.66)$ & $1.13(0.69,1.84)$ & $1.15(0.70,1.87)$ & $0.03(-0.58,0.64)$ \\
\hline$>2$ & $1.24(0.59,2.62)$ & $0.33(0.16,0.67)$ & $0.75(0.39,1.46)$ & $0.99(0.51,1.94)$ & $-0.19(-1.01,0.64)$ \\
\hline Seminal factor present & $p=0.001$ & $p=0.933$ & $p=0.744$ & $p=0.503$ & $p=\mathbf{0 . 0 0 1}$ \\
\hline No & Ref & Ref & Ref & Ref & Ref \\
\hline Yes & $0.36(0.21,0.61)$ & $1.01(0.63,1.61)$ & $1.07(0.71,1.61)$ & $1.13(0.75,1.70)$ & $-1.00(-1.51,-0.49)$ \\
\hline Nr of sexual partners last 3 months ${ }^{1}$ & $p=0.319$ & $p=\mathbf{0 . 0 0 3}$ & $p=\mathbf{0 . 0 2 2}$ & $p=0.095$ & $p=0.310$ \\
\hline 0 & Ref & Ref & Ref & Ref & Ref \\
\hline 1 & $0.50(0.21,1.17)$ & $4.40(1.86,10.41)$ & $2.47(1.02,5.98)$ & $1.61(0.64,4.02)$ & $0.20(-0.85,1.25)$ \\
\hline$>1$ & $0.51(0.17,1.58)$ & $3.05(1.06,8.79)$ & $4.35(1.48,12.74)$ & $2.91(0.99,8.61)$ & $0.82(-0.46,2.10)$ \\
\hline Intravaginal cleansing during bathing & $p=0.408$ & $p=0.057$ & $p=0.557$ & $p=0.178$ & $p=0.099$ \\
\hline No & Ref & Ref & Ref & Ref & Ref \\
\hline Yes & $0.81(0.50,1.32$ & $1.58(0.99,2.53)$ & $0.88(0.58,1.34)$ & $0.75(0.50,1.14)$ & $0.44(-0.08,0.96)$ \\
\hline Contraception use & $p=0.224$ & $p=0.445$ & $p=0.293$ & $p=0.373$ & $p=0.125$ \\
\hline None/Non-Hormonal & Ref & Ref & Ref & Ref & Ref \\
\hline Hormonal & $0.70(0.41,1.22)$ & $0.78(0.47,1.31)$ & $0.83(0.52,1.30)$ & $0.83(0.52,1.32)$ & $-0.53(-1.09,0.04)$ \\
\hline Recent antibiotic use & $p=0.110$ & $p=0.606$ & $p=\mathbf{0 . 0 5 4}$ & $p=\mathbf{0 . 0 5 2}$ & $p=0.832$ \\
\hline No & Ref & Ref & Ref & Ref & Ref \\
\hline Yes & $0.63(0.33,1.21)$ & $0.65(0.38,1.13)$ & $1.76(0.98,3.15)$ & $1.74(1.00,3.03)$ & $-0.64(-1.26,-0.01)$ \\
\hline
\end{tabular}

Results that remained significant (using a $\mathrm{p}=0.05$ cut-off) in the model are depicted in bold. *: non- logistic regression model. qPCR: quantitative polymerase chain reaction. ${ }^{1}$ Data collected at the screening visit up to two months before the enrolment visit. Nr: number. The numbers in each category for the variables are listed in the Additional file 2. 
women was remarkably similar and few differences were seen between the two large groups of reference women in Kenya and South Africa. However, the sex workers and HIV-positive women from Rwanda had the highest G. vaginalis presence, and pregnant women had a higher Lactobacillus concentration. Additionally, this study found that recent sexual exposure negatively affected the presence of L. crispatus, L. vaginalis, and Lactobacillus genus, and that having more than one sexual partner in the last three months was strongly associated with an increased presence of G. vaginalis and L. iners.

This is the first study showing that, in addition to $L$. crispatus, L. vaginalis may play an important role in the health of the vaginal microbiota in African women. $L$. vaginalis together with $L$. crispatus showed the strongest association $(\mathrm{p}<0.001)$ with a healthy Nugent score in the reference group (i.e. adult, non-pregnant, non-sex worker women) and in all women combined. L. vaginalis was present in concentrations above $10^{6} \mathrm{geq} / \mathrm{ml}$ for $36 \%$ of the $28 \%$ of women with detectable $L$. vaginalis. We previously demonstrated a $L$. vaginalis presence of $73 \%$ in healthy and of $8 \%$ in women with BV in a study in Belgium [13]. A recent study that characterized the microbiota among seven women in the US by $16 \mathrm{~S}$ rRNA sequencing identified $L$. vaginalis, in 3 out of 7 healthy women; however, L. vaginalis contributed to less than $0.05 \%$ of the communities [28]. In a study from Burkina Faso, L. vaginalis represented only $0.5 \%$ of sequences in a cluster of 30 participants with dominant genus Lactobacillus, compared to $77 \%$ for $L$. iners and $11 \%$ for $L$. crispatus [4]. In a study that compared vaginal microbiota between unspecified adult populations in Uganda and Korea, L. vaginalis, detected by $16 \mathrm{~S}$ rRNA after isolation on Lactobacillus Rogosa SL agar, was common in Uganda and absent in Korea, whereas L. crispatus was common in both populations [29]. There is also mention of the presence of $L$. vaginalis, detected by Randomly Amplified Polymorphic DNA and 16S rRNA after isolation on Rogosa agar, in a small Swedish study of 20 healthy women in the vagina as well as the rectum [30]. More research is needed to understand the role and function of L. vaginalis, in addition to other Lactobacillus species prevalent in the vaginal niche. MendezSoares and colleagues performed functional genomics of 25 species of vaginal, gastrointestinal and food product lactobacilli [31]. They described differences in genes encoding for proteins that interact with the host, as well as other bacteria, between L. crispatus, L. iners, L. jensenii, L. gasseri. This suggests that these species have different mechanisms for interacting with their environment. Also, it has been shown that different growth limiting factors exist between species. Boskey and colleagues showed in vitro that the growth limiting factor for $L$. vaginalis was a depletion of a metabolite or the buildup of an unspecified toxic waste product; this is in contrast to L. crispatus and L. gasseri in which the growth limiting factor is the lowest point of acidity reached due to species lactic acid production [32].

While several published papers confirm that lactobacilli are the dominant species in a healthy vaginal environment and are replaced by other commensal anaerobes (but remain present in very low numbers) in women with BV, there is a paucity of qPCR data on Lactobacillus genus and species in African populations. Individual species have been characterised in several settings in the US, Europe, Australia and Asia, yet we could identify only three papers for sub-Saharan Africa presenting quantitative data: two from East and one from West Africa. In Niger, 241 asymptomatic women attending a health care clinic were included [33]. Lactobacillus genus was absent in 34 women with a diagnosis of BV by Nugent score (14.2\% of total women). HIV-positive women in Kenya had a L. crispatus mean log concentration just below 6 (copies/swab) which is higher than the $4.7 \log (\mathrm{geq} / \mathrm{ml})$ that we observed in the HIV-positive women in Rwanda [34]. Benning and colleagues retrospectively sequenced the $16 \mathrm{~S}$ rRNA gene in 40 cervicovaginal lavage samples from a Rwandan cohort that included HIV-positive women [35]. Compared to our data in the HIV-positive women, they detected lower presence of Lactobacillus genus (67\% vs $80 \%)$, L. crispatus ( $11 \%$ vs $17 \%)$, L. iners (50\% vs 63\%), and L. vaginalis (11\% vs $30 \%)$. These variations in results may be explained by the small sample size and by the difference in methods used. Pregnancy has been shown to be associated with low bacterial diversity and high levels of lactobacilli, particularly L. crispatus [36,37]. The higher Lactobacillus concentrations that we observed in the pregnant women agrees with a longitudinal study in 22 pregnant, mostly African American women, showing a higher abundance in 16S rRNA V1-V3 of Lactobacillus vaginalis, L. crispatus, L. gasseri and L. jensenii as compared to 20 non-pregnant women, of whom 10 were African American [38]. Similarly, a US longitudinal study of 12 Caucasian healthy women showed a stable Lactobacillus dominant vaginal microbiome (16S rRNA V3-V5) throughout pregnancy [39]. In future, larger and longitudinal studies are needed to adequately characterise the vaginal microbiota among women in sub-Saharan Africa.

L. iners was present in $82 \%$ of BV-negative, in $62 \%$ of intermediate, and in $67 \%$ of BV-positive samples by Nugent score. It is the only Lactobacillus species that was present in high concentrations in samples that are also characterised by high concentrations of $A$. vaginae and $G$. vaginalis. In contrast with the other lactobacilli, $L$. iners did not show an association with vaginal $\mathrm{pH}(\mathrm{p}=$ 0.562 ) and therefore seems to be resilient to a less acidic BV environment. Further, recent exploratory in vitro data 
showed that $G$. vaginalis displaced $L$. crispatus but not $L$. iners [40]. L. iners has been detected as the dominant species in some studies (e.g. in healthy White and Black American women [41]); in combination with L. crispatus in Japanese women [42], Chinese women [43], Estonian women [44], and Caucasian Belgian women [13]; or together with multiple Lactobacillus species in non-Black American women [41]. L. iners has also been shown to be present, though to a lesser extent, in BV-positive samples in other populations (e.g. 6.6\% of sequences in Swedish women) [45].

Sexual behaviours were shown to be associated with concentration of vaginal microbiota. PSA, a validated marker of recent unprotected sexual intercourse in the past 72 hours, was strongly associated with a reduced prevalence of $L$. crispatus and $L$. vaginalis and lower concentrations of Lactobacillus genus. These data are congruent with a contraceptive study which reported that condom use was associated with higher $L$. crispatus concentrations $(+2 \log$ geq $/ \mathrm{ml}, \mathrm{p}<0.001)$ compared to intra uterine device users or women using the rhythm method [46]. This result supports the hypothesis that the exposure to the alkaline semen alters the vaginal microbiota. We reported an increased presence of $G$. vaginalis and $L$. iners with more than 'one sexual partner in the last three months'. BV has been shown to be associated with exposure to a new partner in other reports $[47,48]$. We could not explore this association due to a low number of women reporting a new sex partner. Recently, it has been postulated that certain subgroups of G. vaginalis may cause a different clinical outcome $[49,50]$. Therefore, a new partner could possibly introduce a new G. vaginalis strain and lead to microbial instability. In conclusion, we theorise that the combination of an immediate decrease in Lactobacillus species initiated by alkaline semen, and the acquisition of a new strain of BVassociated bacteria may lead to incident BV episodes.

We detected a higher presence of Lactobacillus species, with the exception of $L$. iners, for women with a low $\mathrm{pH}$. The association of $\mathrm{pH}$ with individual vaginal species has not been described previously but a higher abundance of lactobacilli has been associated with a lower vaginal $\mathrm{pH}$ among 100 cycling Chinese women [43], 494 asymptomatic Estonian women [44], and 396 asymptomatic North American women [20]. The median $\mathrm{pH}$ observed in the reference groups was well above 4.2, the cut-off for which values below are reported as normal [51]. The $\mathrm{pH}$, measured in clinical studies as one of the Amsel criteria, is not often described separately in the literature and data is lacking for women in Africa and in general. A median $\mathrm{pH}$ of 3.6 was described in a Belgian healthy population of 141 women [52]. Moreover, the vaginal $\mathrm{pH}$ in different ethnic groups in North America was as follows: Hispanic 5.0; black 4.7; Asian
4.4 and white 4.2 [20] and for Estonian women the mean value was 4.7 [44].

To our knowledge, the association of parity with a decrease in $L$. vaginalis and $L$. iners presence has not been described previously. This suggests that pregnancy, a period of high oestrogen status with high lactobacilli presence, is followed by a reduction of certain strains of the lactobacilli species. It is possible that the delivery period could disrupt the stable vaginal lactobacillus population attained during pregnancy. This hypothesis needs further study. C. albicans was positively associated with parity in our study. It is known to be associated with pregnancy which may indirectly explain the association with parity. However, a study in 500 Australian pregnant women showed no difference for vaginal candida colonization and parity history [53]. This may indicate that candida colonization does not normalize after delivery.

Though research has shown that intravaginal cleansing is a risk factor for BV [54,55], we did not observe a negative effect of the use of products to externally wash, internally cleanse, or use of products for drying or tightening on the presence or concentrations of species or on BV status by Nugent scoring. On the contrary, in the reference group, a negative association with $A$. vaginae and a positive association with Lactobacillus genus were present among those who reported cleansing during bathing. A systematic review of longitudinal studies concluded that intravaginal cleansing with soap was associated with the development of intermediate vaginal flora and bacterial vaginosis in women with normal vaginal flora at baseline (pooled adjusted odds ratio 1.24, 95\% CI 1.04-1.47) [55]. However, there is also evidence that vaginal practices are highly heterogeneous and, therefore different study populations use different practices and products [56]. Indeed, women in this study mostly performed washing with water during bathing as opposed to using soap or detergents, which may explain our findings.

Although our data showed a link between the presence of $E$. coli and intermediate BV $(\mathrm{p}=0.011)$ there is yet no evidence that $E$. coli is a regular member of the dysbiotic bacterial community. In a recent review by van de Wijgert and colleagues, only three molecular studies reported vaginal microbiome clusters dominated by streptococci, staphylococci, and/or E. coli $[43,57,58]$. It is possible that the association between $E$. coli and BV is confounded by unprotected sex. A study among 44 East African sex workers showed four types of microbiota of which one was dominated by E. coli, mostly present in HIV-positive women, and was distinct from BV [59]. Further, early culture-based studies documented that intercourse led to an increase in vaginal E. coli [60]. This theory could explain the high presence of $E$. coli $(70 \%)$ in the sex worker group in our study. Additionally, the higher presence of $E$ coli in 
the sex workers in our study may indicate sexual practices such as anal sex in addition to perianal contamination during vaginal intercourse [61].

This study has several strengths; sampling from women in three different African countries; sampling populations of women at different risks for STI and HIV; and a quantitative estimation of abundance for well-known dominant organisms of the vaginal microbiota which allowed for extensive profiling of a relatively large number of samples. This study also has several limitations: the sample size of the subgroups was small compared to the large reference groups; the analysis was cross-sectional; multiple testing was performed in defining associations between the variables and species; co-linearity was present e.g. age and parity were correlated $(r=0.65)$, complicating the interpretation of independent effects. Consequently, causation and effects of single associations should be interpreted cautiously. Furthermore, we excluded correlated variables and we did not correct for multiple testing as this was a hypothesis generating analysis. Importantly, the study did not aim to investigate the function of species or sub-species.

\section{Conclusion}

In conclusion, our study in sub-Saharan women provides important baseline data for several important species related to a healthy and dysbiotic vaginal microbiota. Our q PCR results highlight the similarity of Lactobacillus genus and species concentration across two East Africa and one South African site, and between different sub-groups of women. There were also some important differences by pregnancy status and sexual behaviour. Unsurprisingly, we found high concentrations of $L$. iners; but we also found a high concentration of L. vaginalis which has not been well described in other reports. We detected an overall lower presence of Lactobacillus species compared to Asian, US and European populations. These data may explain some of the increased vulnerability of these populations to STI including HIV. Longitudinal studies are needed to study health outcomes, including acquisition of STI and HIV. Additionally, research is needed to understand the role and function of different microbial species and subspecies (e.g. G. vaginalis) in relation to the protection and susceptibility to infection. Ultimately, these data stress the need to invest more research in order to develop novel methods to improve reproductive health and the prevention of infection.

\section{Additional files}

Additional file 1: Overview of the quantitative PCR assays.

Additional file 2: Sociodemographic, behavioural, and clinical characteristics by group.
Additional file 3: Vaginal microbiota species $\mathrm{qPCR}$ presence and $\mathrm{pH}$ by group.

Additional file 4 Distribution plots of quantitative PCR data.

\section{Abbreviations}

AOR: Adjusted odds ratio; BV: Bacterial vaginosis; Cl: confidence interval: CT: Chlamydia trachomatis; HSV-2: herpes simplex virus type 2; KE: Kenya; NG: Neisseria gonorrhoea; PBS: Phosphate buffered saline; PCR: Polymerase chain reaction; PSA: Prostate-specific antigen; qPCR: quantitative polymerase chain reaction; RTI: Reproductive tract infections; RW: Rwanda; SA: South Africa; STI: Sexually transmitted infections; SD: Standard deviation; TV: Trichomonas vaginalis.

\section{Competing interests}

The authors declare that they have no competing interests.

\section{Authors' contributions}

Conceived and designed the vaginal biomarkers project: VJ, JVDW, KM, SD, MM, HV, GN, RV, TC, JM, LH. Analysed the data: JM. Contributed reagents/ materials/analysis tools: TC, RV, LH, PC. Wrote the manuscript: VJ. Contributed writing: JVDW, TC, JM, LH, HV, RV and PC. Revised the paper: all co-authors. All authors read and approved the final manuscript.

\section{Acknowledgements}

The project was funded by the European \& Developing Countries Clinical Trials Partnership (IP_2007_33070_001) and the Research Foundation Flanders (FWO - 3GA13210). The funders had no role in study design, data collection and analysis, decision to publish, or preparation of the manuscript. We thank Dr Suzanna Francis for reviewing the manuscript.

\section{Vaginal Biomarkers group}

\section{ICRH Kenya, Mombasa, Kenya}

Kishor Mandaliya (overall project manager); Lou Dierick (overall study administrator); Mary Mwaura (site principal investigator); Walter Jaoko (site co-investigator); Eunice Irungu (site study coordinator); Christine Katingima (study clinician); Mercy Maina and Jane Wanjiru Mazera (study nurses); Josephine Gichuru and Grace Aketch Onuki (counselors); Mary Kiambi (community health worker); Mary Thiong'o (data manager); Salome Wanjiku and Patricia Nduku (data capturer); Carol Njeru and Bernard Mbogho (research assistants); Sammy Wambua (lab manager); Rachel Sidi Baya, Emmanuel Moffat Onduko, Patrick Katana Kombo, Simon Chengo Masha, and Mary Ndinda John (laboratory technologists) Kevin Odeyo and Dora Ngala (intern-laboratory technologists); Collins Odero (quality assurance monitor).

Wits Reproductive Health \& HIV Institute, University of Witwatersrand, Johannesburg, South Africa

Sinead Delany-Moretlwe (site principal investigator); Vinodh Aroon Edward (site co-investigator); Krishnaveni Reddy (site study coordinator); Nina Von Knorring and Ishania Mahabeer (study clinicians); Johannah Nkoleleng Mashilo and Ntombifuthi Mnyandu (study nurses); Keneuoe Mokoatle (clinical quality improvement mentor); Siyabulela Nani (data manager); Gugu Tshabalala and Thembisile Hope Mngwevu (data capturers); Noxolo Mtabane, Puseletso Maria Masalesa and Zodidi Kumase (community health workers); Sefora Dipolelo Mohale (community liaison officer); Mavis Mantshitseng Madi (administrator); Mandla Mlotshwa (medical scientist/ lab manager); Pholo Wilson Maenetje (medical scientist); Nishanee Arjun (quality assurance monitor); Debra De Assis Rosa (research operations manager). Rinda Ubuzima, Kigali, Rwanda

Gilles F. Ndayisaba (site principal investigator); Evelyne Kestelyn (co-investigator); Ammiel Gasarabwe (site study coordinator); Servaas Van Eeckhoudt and Stephen Agaba (study clinicians); Rosette Busasa (study nurse); Deogratias Nshimuyimana and Grace Umutoni (data capturers); Vincent Karangwa (administrator); Claire Bukuru (administrative research assistant); Alice Fiat (lab manager); Lambert Mwambarangwe and Viateur Musengamana (laboratory technicians); Jeanine Nyinawabega (quality assurance monitor). Institute of Tropical Medicine, Antwerp, Belgium

Vicky Jespers (coordinating investigator); Liselotte Hardy (study management coordinator); Tania Crucitti (laboratory management coordinator); Joris Menten (statistics coordinator); Céline Schurmans (monitoring coordinator); Harry van Loen (data management coordinator); Anne Buvé (epidemiologist); Jordan Kyongo (PhD student); Kevin Ariën and Guido Vanham (virology); 
Said Abdellati and Vicky Cuylaert (laboratory technicians); Wendy Thys and An lelegems (administrators); Lieve Casier (shipment logistics).

\section{University Ghent, Ghent, Belgium}

Hans Verstraelen and Marleen Temmerman (co-investigators), Rita Verhelst and Mario Vaneechoutte (laboratory co-investigators); Piet Cools (PhD student); Bart Saerens (laboratory technician).

\section{AMC-CPCD, Amsterdam, The Netherlands}

Janneke van de Wijgert (co-investigator); Friso Janssen (administrator).

MRC CTU, London, United Kingdom

Sheena McCormack (co-investigator); Sarah Joseph (laboratory coordinator). London School of Hygiene and Tropical Medicine, London, United Kingdom Richard Hayes and Suzanna Francis (co-investigators); Kathy Baisley (statistician)

\section{MITU, Mwanza, Tanzania}

Saidi Kapiga (Director of MITU); Aura Andreasen (laboratory); John Changalucha (Head of NIMR and head of the lab during the time of the study); Kaballa Maganja (study coordinator); Clemens Masesa (data manager).

\section{Author details}

'Department of Public Health, Unit of Epidemiology and Control of HIV/STD, Institute of Tropical Medicine, Nationalestraat 155, B-2000 Antwerp, Belgium. ${ }^{2}$ Department of Clinical Infection, Microbiology and Immunology, Institute of Infection and Global Health, University of Liverpool, Liverpool, UK. ${ }^{3}$ Laboratory Bacteriology Research, University Gent, Ghent, Belgium. ${ }^{4}$ International Center for Reproductive Health (ICRH), Ghent University, Ghent, Belgium. ${ }^{5}$ Department of Obstetrics and Gynaecology, Faculty of Medicine and Health Sciences, Ghent University, Ghent, Belgium. 'Wits Reproductive Health \& HIV Institute, University of Witwatersrand, Johannesburg, South Africa. ${ }^{7}$ ICRH Kenya, Mombasa, Kenya. ${ }^{8}$ Rinda Ubuzima, Kigali, Rwanda. ${ }^{9}$ Department of Clinical Sciences, Institute of Tropical Medicine, Antwerp, Belgium. ${ }^{10}$ Department of Clinical Sciences, HIV/STI Reference Laboratory, Institute of Tropical Medicine, Antwerp, Belgium.

\section{Received: 12 September 2014 Accepted: 10 February 2015}

\section{Published online: 04 March 2015}

\section{References}

1. Atashili J, Poole C, Ndumbe PM, Adimora AA, Smith JS. Bacterial vaginosis and HIV acquisition: a meta-analysis of published studies. AIDS. 2008;22:1493-501.

2. Taylor $B D$, Darville $T$, Haggerty $C L$. Does bacterial vaginosis cause pelvic inflammatory disease? Sex Transm Dis. 2013;40:117-22.

3. Li J, McCormick J, Bocking A, Reid G. Importance of vaginal microbes in reproductive health. Reprod Sci. 2012;19:235-42.

4. Frank DN, Manigart O, Leroy V, Meda N, Valea D, Zhang W, et al. Altered vaginal microbiota are associated with perinatal mother-to-child transmission of HIV in African women from Burkina Faso. J Acquir Immune Defic Syndr. 2012;60:299-306

5. Cherpes TL, Meyn LA, Krohn MA, Lurie JG, Hillier SL. Association between acquisition of herpes simplex virus type 2 in women and bacterial vaginosis. Clin Infect Dis. 2003;37:319-25.

6. King CC, Jamieson DJ, Wiener J, Cu-Uvin S, Klein RS, Rompalo AM, et al. Bacterial vaginosis and the natural history of human papillomavirus. Infect Dis Obstet Gynecol. 2011;2011:319460.

7. Wiesenfeld HC, Hillier SL, Krohn MA, Landers DV, Sweet RL. Bacterial vaginosis is a strong predictor of Neisseria gonorrhoeae and Chlamydia trachomatis infection. Clin Infect Dis. 2003;36:663-8.

8. Buve A, Jespers V, Crucitti T, Fichorova RN. The vaginal microbiota and susceptibility to HIV. AIDS. 2014;24:2333-44.

9. Srinivasan S, Fredricks DN. The human vaginal bacterial biota and bacterial vaginosis. Interdiscip Perspect Infect Dis. 2008;2008:750479.

10. van de Wijgert JH, Borgdorff $H$, Verhelst $R$, Crucitti T, Francis S, Verstraelen $H$ et al. The vaginal microbiota: what have we learned after a decade of molecular characterization? PLoS One. 2014;9:e105998.

11. Mitchell C, Marrazzo J. Bacterial vaginosis and the cervicovaginal immune response. Am J Reprod Immunol. 2014;71:555-63.

12. Hickey RJ, Zhou X, Pierson JD, Ravel J, Forney L. Understanding vaginal microbiome complexity from an ecological perspective. Transl Res. 2012;160:267-82

13. Jespers V, Menten J, Smet H, Poradosu S, Abdellati S, Verhelst R, et al. Quantification of bacterial species of the vaginal microbiome in different groups of women, using nucleic acid amplification tests. BMC Microbiol. 2012;12:83.

14. Mauck CK. Biomarkers of semen exposure. Sex Transm Dis. 2009;36:S81-3.

15. Jespers V, Crucitti T, Menten J, Verhelst R, Mwaura M, Mandaliya K, et al. Prevalence and correlates of bacterial vaginosis in different sub-populations of women in sub-Saharan Africa: a cross-sectional study. PLoS One. 2014;9:e109670.

16. Braunstein $\mathrm{SL}$, Ingabire CM, Kestelyn E, Uwizera AU, Mwamarangwe L, Ntirushwa J, et al. High human immunodeficiency virus incidence in a cohort of Rwandan female sex workers. Sex Transm Dis. 2011:38:385-94

17. Braunstein SL, Ingabire CM, Geubbels E, Vyankandondera J, Umulisa MM, Gahiro E, et al. High burden of prevalent and recently acquired HIV among female sex workers and female HIV voluntary testing center clients in Kigali, Rwanda. PLoS One. 2011;6:e24321.

18. Nugent RP, Krohn MA, Hillier SL. Reliability of diagnosing bacterial vaginosis is improved by a standardized method of gram stain interpretation. J Clin Microbiol. 1991;29:297-301.

19. dos Lopes Santos Santiago G, Tency I, Verstraelen H, Verhelst R, Trog M, Temmerman $M$, et al. Longitudinal qPCR study of the dynamics of $L$. crispatus, L. iners, A. vaginae, (sialidase positive) G. vaginalis, and P. bivia in the vagina. PLoS One. 2012;7:e45281.

20. Ravel J, Gajer P, Abdo Z, Schneider GM, Koenig SS, McCulle SL, et al. Vaginal microbiome of reproductive-age women. Proc Natl Acad Sci U S A. 2011;108 Suppl 1:4680-7.

21. Tamrakar R, Yamada T, Furuta I, Cho K, Morikawa M, Yamada H, et al. Association between Lactobacillus species and bacterial vaginosis-related bacteria, and bacterial vaginosis scores in pregnant Japanese women. BMC Infect Dis. 2007;7:128

22. Zariffard MR, Saifuddin M, Sha BE, Spear GT. Detection of bacterial vaginosis-related organisms by real-time PCR for Lactobacilli, Gardnerella vaginalis and Mycoplasma hominis. FEMS Immunol Med Microbiol. 2002;34:277-81.

23. Mauck CK, Lai JJ, Weiner DH, Chandra N, Fichorova RN, Dezzutti CS, et al. Toward early safety alert endpoints: exploring biomarkers suggestive of microbicide failure. AIDS Res Hum Retroviruses. 2013;29:1475-86.

24. Byun $\mathrm{R}$, Nadkarni MA, Chhour KL, Martin FE, Jacques NA, Hunter N. Quantitative analysis of diverse Lactobacillus species present in advanced dental caries. J Clin Microbiol. 2004:42:3128-36.

25. De Backer E, Verhelst R, Verstraelen H, Alqumber MA, Burton JP, Tagg JR, et al. Quantitative determination by real-time PCR of four vaginal Lactobacillus species, Gardnerella vaginalis and Atopobium vaginae indicates an inverse relationship between L. gasseri and L. iners. BMC Microbiol. 2007:7:115.

26. Chern EC, Siefring S, Paar J, Doolittle M, Haugland RA. Comparison of quantitative PCR assays for Escherichia coli targeting ribosomal RNA and single copy genes. Lett Appl Microbiol. 2011;52:298-306.

27. Menard JP, Fenollar F, Raoult D, Boubli L, Bretelle F. Self-collected vaginal swabs for the quantitative real-time polymerase chain reaction assay of Atopobium vaginae and Gardnerella vaginalis and the diagnosis of bacterial vaginosis. Eur J Clin Microbiol Infect Dis. 2011;31:513-8.

28. Hickey RJ, Abdo Z, Zhou X, Nemeth K, Hansmann M, Osborn III TW, et al. Effects of tampons and menses on the composition and diversity of vaginal microbial communities over time. BJOG. 2013;120:695-704.

29. Jin L, Tao L, Pavlova SI, So JS, Kiwanuka N, Namukwaya Z, et al. Species diversity and relative abundance of vaginal lactic acid bacteria from women in Uganda and Korea. J Appl Microbiol. 2007;102:1107-15.

30. Gustafsson RJ, Ahrne S, Jeppsson B, Benoni C, Olsson C, Stjernquist M, et al. The Lactobacillus flora in vagina and rectum of fertile and postmenopausal healthy Swedish women. BMC Womens Health. 2011;11:17.

31. Mendes-Soares $H$, Suzuki H, Hickey RJ, Forney LJ. Comparative functional genomics of Lactobacillus spp. reveals possible mechanisms for specialization of vaginal lactobacilli to their environment. J Bacteriol. 2014;196:1458-70.

32. Boskey ER, Telsch KM, Whaley KJ, Moench TR, Cone RA. Acid production by vaginal flora in vitro is consistent with the rate and extent of vaginal acidification. Infect Immun. 1999;67:5170-5.

33. Anukam KC, Osazuwa EO, Ahonkhai I, Reid G. Lactobacillus vaginal microbiota of women attending a reproductive health care service in Benin city, Nigeria. Sex Transm Dis. 2006;33:59-62.

34. Mitchell C, Balkus JE, Fredricks D, Liu C, McKernan-Mullin J, Frenkel LM, et al. Interaction between lactobacilli, bacterial vaginosis-associated bacteria, and 
HIV Type 1 RNA and DNA Genital shedding in U.S. and Kenyan women. AIDS Res Hum Retroviruses. 2013;29:13-9.

35. Benning L, Golub ET, Anastos K, French AL, Cohen M, Gilbert D, et al. Comparison of lower genital tract microbiota in HIV-infected and uninfected women from Rwanda and the US. PLoS One. 2014;9:e96844.

36. Aagaard K, Riehle K, Ma J, Segata N, Mistretta TA, Coarfa C, et al. metagenomic approach to characterization of the vaginal microbiome signature in pregnancy. PLoS One. 2012;7:e36466.

37. Petricevic L, Domig KJ, Nierscher FJ, Krondorfer I, Janitschek C, Kneifel W, et al. Characterisation of the oral, vaginal and rectal Lactobacillus flora in healthy pregnant and postmenopausal women. Eur J Obstet Gynecol Reprod Biol. 2012;160:93-9.

38. Romero R, Hassan SS, Gajer P, Tarca AL, Fadrosh DW, Nikita L, et al. The composition and stability of the vaginal microbiota of normal pregnant women is different from that of non-pregnant women. Microbiome. 2014;2:4.

39. Walther-Antonio MR, Jeraldo P, Berg Miller ME, Yeoman CJ, Nelson KE, Wilson BA, et al. Pregnancy's stronghold on the vaginal microbiome. PLoS One. 2014;9:e98514.

40. Castro J, Henriques A, Machado A, Henriques M, Jefferson KK, Cerca N. Reciprocal interference between Lactobacillus spp. and Gardnerella vaginalis on initial adherence to epithelial cells. Int J Med Sci. 2013;10:1193-8.

41. Zhou X, Brown CJ, Abdo Z, Davis CC, Hansmann MA, Joyce P, et al. Differences in the composition of vaginal microbial communities found in healthy Caucasian and black women. ISME J. 2007;1:121-33.

42. Zhou X, Hansmann MA, Davis CC, Suzuki H, Brown CJ, Schutte U, et al. The vaginal bacterial communities of Japanese women resemble those of women in other racial groups. FEMS Immunol Med Microbiol. 2010;58:169-81.

43. Ling Z, Kong J, Liu F, Zhu H, Chen X, Wang Y, et al. Molecular analysis of the diversity of vaginal microbiota associated with bacterial vaginosis. BMC Genomics. 2010;11:488.

44. Drell T, Lillsaar T, Tummeleht L, Simm J, Aaspollu A, Vain E, et al. Characterization of the vaginal micro- and mycobiome in asymptomatic reproductive-age Estonian women. PLoS One. 2013;8:e54379.

45. Shipitsyna E, Roos A, Datcu R, Hallen A, Fredlund H, Jensen JS, et al. Composition of the vaginal microbiota in women of reproductive age-sensitive and specific molecular diagnosis of bacterial vaginosis is possible? PLoS One. 2013:8:e60670.

46. Ma L, Lv Z, Su J, Wang J, Yan D, Wei J, et al. Consistent condom use increases the colonization of Lactobacillus crispatus in the vagina. PLoS One. 2013;8:e70716.

47. Marrazzo JM. Interpreting the epidemiology and natural history of bacterial vaginosis: are we still confused? Anaerobe. 2011;17:186-90.

48. Schwebke JR, Desmond R. Risk factors for bacterial vaginosis in women at high risk for sexually transmitted diseases. Sex Transm Dis. 2005;32:654-8.

49. Paramel Jayaprakash T, Schellenberg JJ, Hill JE. Resolution and characterization of distinct cpn60-based subgroups of Gardnerella vaginalis in the vaginal microbiota. PLoS One. 2012;7:e43009.

50. dos Lopez Santos Santiago GL, Deschaght P, El AN, Kiama TN, Verstraelen H, Jefferson KK, et al. Gardnerella vaginalis comprises three distinct genotypes of which only two produce sialidase. Am J Obstet Gynecol. 2011;204:450-7.

51. O'Hanlon DE, Moench TR, Cone RA. In vaginal fluid, bacteria associated with bacterial vaginosis can be suppressed with lactic acid but not hydrogen peroxide. BMC Infect Dis. 2011;11:200.

52. Kyongo JK, Jespers V, Goovaerts O, Michiels J, Menten J, Fichorova RN, et al. Searching for lower female genital tract soluble and cellular biomarkers: defining levels and predictors in a cohort of healthy Caucasian women. PLoS One. 2012;7:e43951.

53. Roberts CL, Rickard K, Kotsiou G, Morris JM. Treatment of asymptomatic vaginal candidiasis in pregnancy to prevent preterm birth: an open-label pilot randomized controlled trial. BMC Pregnancy Childbirth. 2011;11:18.

54. Hilber AM, Francis SC, Chersich M, Scott P, Redmond S, Bender N, et al. Intravaginal practices, vaginal infections and HIV acquisition: systematic review and meta-analysis. PLoS One. 2010;5:e9119.

55. Low N, Chersich MF, Schmidlin K, Egger M, Francis SC, van de Wijgert JH, et al. Intravaginal practices, bacterial vaginosis, and HIV infection in women: individual participant data meta-analysis. PLoS Med. 2011;8:e1000416.

56. Hull T, Hilber AM, Chersich MF, Bagnol B, Prohmmo A, Smit JA, et al. Prevalence, motivations, and adverse effects of vaginal practices in Africa and Asia: findings from a multicountry household survey. J Womens Health (Larchmt). 2011;20:1097-109.
57. Hernandez-Rodriguez C, Romero-Gonzalez R, Albani-Campanario M, Figueroa-Damian R, Meraz-Cruz N, Hernandez-Guerrero C. Vaginal microbiota of healthy pregnant Mexican women is constituted by four Lactobacillus species and several vaginosis-associated bacteria. Infect Dis Obstet Gynecol. 2011;2011:851485.

58. Sha BE, Zariffard MR, Wang QJ, Chen HY, Bremer J, Cohen MH, et al. Female genital-tract HIV load correlates inversely with Lactobacillus species but positively with bacterial vaginosis and Mycoplasma hominis. J Infect Dis. 2005;191:25-32.

59. Schellenberg JJ, Links MG, Hill JE, Dumonceaux TJ, Kimani J, Jaoko W, et al. Molecular definition of vaginal microbiota in East African commercial sex workers. Appl Environ Microbiol. 2011;77:4066-74.

60. Eschenbach DA, Patton DL, Hooton TM, Meier AS, Stapleton A, Aura J, et al. Effects of vaginal intercourse with and without a condom on vaginal flora and vaginal epithelium. J Infect Dis. 2001;183:913-8.

61. Tameliene R, Barcaite E, Stoniene D, Buinauskiene J, Markuniene E, Kudreviciene A, et al. Escherichia coli colonization in neonates: prevalence, perinatal transmission, antimicrobial susceptibility, and risk factors. Medicina (Kaunas). 2012;48:71-6.

\section{Submit your next manuscript to BioMed Central and take full advantage of:}

- Convenient online submission

- Thorough peer review

- No space constraints or color figure charges

- Immediate publication on acceptance

- Inclusion in PubMed, CAS, Scopus and Google Scholar

- Research which is freely available for redistribution 